\title{
DECISÕES PARA O CRESCIMENTO DA MULTIEVENTOS
}

\author{
DECISIONS FOR THE GROWTH OF MULTIEVENTS \\ DECISIONES PARA EL CRECIMIENTO DE LA MULTIEVENTOS
}

Dr. Anete Alberton

Universidade do Vale do Itajaí

anete@univali.br

M.sC Daniele Cristine Maske

Grupo Uniasselvi

danimaske@hotmail.com

M.sC Pedro Mascarenhas de Souza Pinheiro

Universidade Federal de Pelotas

pedromsp@ig.com.br

M.sC. Rosana Arruda Cruz

Universidade do Vale do Itajaí rosanaarruda@univali.br

Data de Submissão: 27/07/2012

Data de Aprovação: 22/07/2013

\section{RESUMO}

O caso para ensino apresenta a situação de uma empresa do ramo de eventos, montada por dois amigos de longa data, com experiência técnica e científica na área, o caso mostra desde a concepção até o momento de decisão pela expansão da Multieventos. A empresa é de pequeno porte e atende, em um primeiro momento, a eventos empresariais. Por meio do sucesso que a empresa estava obtendo, os sócios, Léia e Geovan, decidiram que seria hora de expandir os negócios para ampliar sua atuação no mercado e também para a satisfação pessoal. Nesta condição, eles fazem uma nova análise do mercado, conhecendo o município onde estão localizados, procurando os atuais e potenciais parceiros e fornecedores e conhecendo a concorrência existente na área de Balneário Camboriú e região. Para tornar este crescimento em realidade, os sócios procuram por opções de financiamento para viabilizar a ideia. O caso enfatiza o empreendedorismo, o marketing e a análise de investimentos. Pode ser utilizado em cursos de graduação e pós-graduação em turismo e hotelaria, ou que tenham disciplinas de finanças, marketing e vendas, empreendedorismo e eventos.

\begin{abstract}
This teaching case presents the situation of a company in the events sector, set up by two old friends with technical and scientific experience in the area. It shows the path from its conception up until the decision to expand Multievents, a small company that caters mainly for corporate events. Due to its success, the partners, Léia and Geovan, decided it was time to expand their businesses in order to increase their operations in the market, as well as for their own personal satisfaction. The partners carried out a new market analysis of the city where Multieventos is located, looking for current and potential partners and suppliers and investigating the competition that exists in Balneário Camboriú and the surrounding region. To make this growth a reality, the partners looked for financing options. This teaching case emphasizes Entrepreneurship, Marketing, and Investment Analysis. It can be used in undergraduate and postgraduate courses in tourism and Hotel Management or others that offer disciplines in financial, marketing and sales, entrepreneurship and events.
\end{abstract}


Este caso para la enseñanza presenta la situación de una empresa del ramo de eventos, montada por dos antiguos amigos con experiencia técnica y científica en el área, y muestra desde la concepción hasta el momento de la decisión de la expansión de la Multieventos. La empresa es de pequeño porte y atendía, en un primer momento, eventos empresariales. Por medio del éxito que la empresa estaba obteniendo, los socios, Léia y Geovan, decidieron que sería hora de expandir los negocios para ampliar su actuación en el mercado y también para su satisfacción personal. En esta condición, ellos hacen un nuevo análisis de mercado, conociendo el municipio en el que están ubicados, buscando a sus actuales y potenciales asociados y proveedores y conociendo la competencia existente en el área de Balneário Camboriú y región. Para transformar este crecimiento en una realidad, los socios buscan opciones de financiación para viabilizar la idea. El caso hace hincapié en el emprendedorismo, el marketing y el análisis de inversiones. Puede ser utilizado en cursos de grado y posgrado en turismo y hotelería, o que tengan asignaturas de finanzas, marketing y ventas, emprendedorismo y eventos.

\section{INTRODUÇÃO}

Léia e Geovan são amigos desde que iniciaram a faculdade de Turismo e Hotelaria. Sempre fizeram trabalhos de aula juntos e, já no primeiro ano de faculdade, descobriram que o que realmente gostavam era trabalhar com eventos. Ambos conseguiram empregos na área. Primeiramente, Geovan foi estagiário durante seu período de férias numa grande empresa de eventos em sua cidade natal, e Léia foi estagiária de uma empresa de eventos com foco em casamentos e formaturas em Balneário Camboriú, a Total Eventos. Após o período de estágio, Léia foi contratada pela empresa. Em alguns meses Geovan também passou a trabalhar na Total Eventos. Porém, à medida que concluíam o curso, eles definitivamente sabiam que a chance de crescimento dentro da empresa na qual trabalhavam não atendia à expectativa de ambos. Foi aí que começou o sonho de ter o próprio negócio, a busca pela autorrealização.

\section{VONTADE POR EMPREENDER}

Em busca de uma nova oportunidade de negócio, eles fizeram um estudo de mercado, conhecendo a concorrência existente na cidade e região, os potenciais clientes e áreas para onde poderiam crescer, bem como possíveis parceiros e fornecedores com quem poderiam trabalhar. Como a análise do cenário foi positiva, na visão dos sócios, para um empresa deste ramo, decidiram continuar na área de eventos, pois era um mercado em expansão na cidade e ambos já tinham experiência no ramo. Eles levaram a ideia a sério e inicialmente os finais de semana eram o palco para montar o plano de negócios de sua empresa. Também fizeram cursos no SEBRAE para aprimorar seus conhecimentos em administração de empresas. No ano em que se formaram, Léia e Geovan estavam com o projeto da empresa montado. Saíram de seus empregos e iniciaram o projeto de seus sonhos: nasceu a Multieventos.

\section{NASCE A MULTIEVENTOS}

A empresa Multieventos iniciou suas atividades no ano de 2008 na cidade de Balneário Camboriú. O foco da empresa era atender eventos empresariais de pequeno porte, como reuniões, eventos de lançamentos de produtos, palestras e treinamentos. Eles organizavam o evento por completo e faziam o acompanhamento durante sua realização. Os serviços de audiovisuais, sonorização, espaço para o evento e coffee breaks eram terceirizados, porém todos os seus fornecedores foram escolhidos antecipadamente com muito cuidado. Para conseguir os primeiros clientes, Léia, que era muito criativa, elaborou um flyer que apresentava os serviços da Multieventos. Eles listaram as potenciais empresas que poderiam se tornar clientes e Geovan, que era bastante persuasivo e tinha uma ampla rede de contatos, fez as visitas para apresentar suas propostas. 
Apesar de ser uma pequena empresa, os jovens empreendedores primavam pelo bom atendimento ao cliente e pela qualidade de seus serviços. Eles prestavam seus serviços de forma rápida e eficaz, resolviam problemas com muita eficiência, mantinham contato contínuo com seus fornecedores e clientes.

Após o primeiro ano de funcionamento, apesar de iniciarem devagar, eles já conseguiram visualizar seus pontos fortes e fracos, fazendo um balanço do ano e planejando novas estratégias e ações para o próximo ano. Léia e Geovan ansiavam por uma empresa maior e de destaque no mercado. Após algumas mudanças de fornecedores e oferta de serviços adicionais, eles iniciaram o ano de 2009 muito bem. A empresa estava começando a se tornar conhecida pelo marketing boca a boca, a demanda aumentou e o tamanho dos eventos requisitados também.

\section{EM FASE DE MUDANÇAS}

Foi no final de 2009 que eles realmente perceberam que a empresa não era mais uma "brincadeira de alunos recém-formados", mas algo que deu certo e que era sério e profissional, que tinha grande chance de crescer e se destacar no mercado. Por este motivo decidiram que 2010 seria o ano das mudanças, de decidir um novo rumo para a Multieventos.

Geovan chamou Léia para uma reunião de final de ano e fez a proposta das mudanças:

"Estamos às vésperas de completar dois anos de fundação da nossa empresa, iniciamos devagar, com alguns problemas, porém ao longo dos anos fomos adquirindo mais experiência e já somos uma empresa lembrada no mercado de eventos. Crescemos e nossa carreira profissional também está melhorando. O faturamento da empresa teve crescimento considerável desde o primeiro ano. Porém em momento algum assumimos maiores desafios. Acho que chegou o momento de assumirmos alguns riscos, inovarmos e crescermos. Já nos conhecemos há oito anos, trabalhamos juntos há dois anos e sei que o sonho de ter uma empresa de porte maior, atender grandes eventos, ter uma empresa de destaque e consolidar a carreira profissional não é só meu."

Léia concordava com as palavras de Geovan. Juntos decidiram que, em janeiro, mês com menos eventos, seria a época ideal para decidirem o novo rumo da Multieventos. Decisão esta que dependeria de diferentes análises a ser consideradas. E foi em janeiro que priorizaram as mudanças na empresa. Na primeira reunião do ano decidiram dividir melhor as tarefas: Léia ficou responsável pelo setor administrativo-financeiro e Geovan passou a se dedicar à área de marketing, vendas e acompanhamento dos eventos. Revisaram o plano de negócios inicial e decidiram que teriam que fazer mudanças na área de marketing e vendas, ou seja, rever a situação atual do mercado, seus concorrentes e fornecedores. Além disso, teriam que arriscar e fazer um financiamento para investir na empresa e expandir. Para ambos os sócios, esta seria a decisão mais difícil de ser tomada, por se tratar de uma quantia financeira, necessária para a alavancagem da Multieventos ao patamar esperado por Léia e Geovam. Desta decisão dependeria, enfim, o futuro da empresa. Porém, ela não poderia ser tomada sem análises anteriores de mercado e de perspectivas futuras. Seria o passo definitivo dos sócios para tornar a Multieventos uma forte empresa no setor.

Queriam se tornar profissionais ainda mais sérios e reconhecidos no mercado. Para isso, fornecedores idôneos, éticos e ambiental e socialmente responsáveis, trabalhando com tecnologia de ponta (recursos audiovisuais e sonorização) eram necessários. A escolha por trabalhar com fornecedores responsáveis, além de uma garantia de qualidade de serviço, era vista por Léia e Geovan como um possível diferencial de marketing para a empresa, tendo sido prioritário para os sócios na adoção do novo rumo da Multieventos. Também queriam sair da sala montada na casa dos pais de Léia para um escritório profissional, contratando funcionários para suporte às atividades administrativas e operacionais e investindo na imagem e na divulgação da empresa. Desta forma, acreditavam os sócios que a Multieventos passaria uma imagem mais profissional a seus clientes, parceiros e fornecedores, dando mais credibilidade junto a estes atores. Léia analisou as contas da empresa e consultou bancos e financiadoras quanto à possibilidade de um financiamento para investimento na empresa. Geovan fez um levantamento do mercado, dos concorrentes e tipo de serviços que prestavam e dos fornecedores potenciais. 


\section{A PRAÇA DE ATUAÇÃO DA MULTIEVENTOS}

A primeira tarefa de Geovan foi contextualizar a cidade na qual a Multieventos atua. Ele fez um estudo, visando conhecer as particularidades da cidade de Balneário Camboriú, sua estrutura e economia para ajudar na decisão de expansão da empresa, para os sócios, era importante saber se a cidade, por não se tratar de uma capital, comportava crescimentos de empresas desta área. Era intenção buscar descobrir, por meio dele, quais pontos poderiam ser diferenciais em uma empresa de eventos na região.

As principais atividades econômicas do município são o turismo e a construção civil. Durante todo o ano a cidade recebe não apenas turistas brasileiros, mas do mundo todo e a construção civil é altamente valorizada. A cidade conta com uma invejável infraestrutura de urbanização, saneamento, paisagismo, saúde, segurança e educação, o que garantiu ao município o $7^{\circ}$ lugar no Índice de Desenvolvimento Humano do Brasil (IDH) em pesquisa realizada pela ONU (2010). Foi eleito o município com melhor qualidade de vida do litoral catarinense, sendo a segunda do Estado, permanecendo atrás apenas de Florianópolis.

Além disso, Balneário Camboriú é uma cidade que oferece uma vasta gama de serviços, ótima infraestrutura e qualidade de vida, o que atrai turistas e investidores de todas as partes do mundo. É uma cidade muito diversificada, que atrai especialmente os públicos das classes A e $B$, e mais recentemente, também atende aos interesses da classe média (IMÓVEIS \& CIA, 2012).

O setor turístico vem sendo alavancado pela nova classe média brasileira que colocou o turismo no seu orçamento familiar. A Associação Brasileira das Operadoras de Turismo justifica o aumento previsto de $20 \%$ no faturamento em 2011 por meio do consumo da classe média. Operadoras e agências estão cada vez mais atentos a estes consumidores, oferecendo produtos e prazos de pagamento diferenciados para atender às expectativas deles (ECONOMIA \& NEGÓCIOS, 2012).

Da mesma forma, o setor imobiliário é alavancado pela estabilidade econômica em nosso país. E além de atender a um público que procura por luxo e sofisticação, o interesse da classe média em adquirir imóveis no litoral também está incrementando a demanda na construção civil. As construtoras estão percebendo a necessidade de investir também nos bairros, onde o valor dos imóveis é menor e atende a uma gama maior de consumidores. Dessa forma, o número de apartamentos entregues por ano, que gira em torno de 1.000 unidades na área central, se tornará ainda maior (O SOL DIÁRIO, 2012).

Na cidade de Balneário Camboriú é possível presenciar o paraíso natural amparado por muito conforto e diversão da vida urbana. Além disso, o município possui uma ampla estrutura para recepcionar o turismo de eventos e negócios. Acompanhando as tendências do turismo mundial, a cidade investe numa infraestrutura de qualidade que já possibilita a realização de eventos de alto nível (PREFEITURA MUNICIPAL DE BALNEÁRIO CAMBORIÚ, 2010). O aumento da demanda turística em Balneário Camboriú e a forte mobilização da construção civil fazem aumentar também o número de empreendimentos relacionados direta ou indiretamente com estes setores da economia, que podem de várias maneiras elevar as expectativas de negócios para o setor de eventos.

O hábito de se realizar festas de lançamentos de incorporações no setor da construção civil torna as empresas construtoras em potenciais clientes para a realização de eventos no município. A exigência de um serviço de qualidade neste momento, por parte destas construtoras, é muito grande, por ser este o primeiro contato entre o potencial comprador e o imóvel, mesmo que seja somente com a apresentação da planta do mesmo, ou com o lançamento da pedra fundamental da construção. $O$ fato de o mercado imobiliário ser uma das principais atividades econômicas do município contribui para esta alta exigência por serviços de qualidade.

\section{COMO ESTÁ A CONCORRÊNCIA?}

Geovan descobriu cinco empresas que atuam no mesmo ramo na cidade (Quadro1): 


\begin{tabular}{|c|c|}
\hline Concorrentes & Descrição \\
\hline +Eventos & $\begin{array}{l}\text { Com quinze anos de atuação, foi a primeira empresa do ramo a ser constituída na } \\
\text { cidade, especializada em eventos empresariais, tem como seus maiores clientes as } \\
\text { grandes revendedoras de automóveis. Seus sócios, porém, não se atualizaram e } \\
\text { seus serviços não têm sido inovadores. }\end{array}$ \\
\hline $\begin{array}{l}\text { M\&G Asses- } \\
\text { soria }\end{array}$ & $\begin{array}{l}\text { Possui dez anos de experiência, trabalha prioritariamente com eventos particulares, } \\
\text { tendo organizado neste tempo centenas de eventos, como casamentos, aniversários, } \\
\text { bodas e outras grandes festas da alta sociedade. }\end{array}$ \\
\hline $\begin{array}{l}\text { Inarte } \\
\text { Produções }\end{array}$ & $\begin{array}{l}\text { Inaugurada no mesmo ano da Multieventos, também busca seu espaço no mercado, } \\
\text { atua tanto em eventos particulares quanto empresariais, trabalha com clientes de } \\
\text { menor poder aquisitivo, mas em compensação garante um grande número de tra- } \\
\text { balho. Para realizar eventos que atendam a seu público-alvo, a empresa não trabalha } \\
\text { com equipamentos de última geração. }\end{array}$ \\
\hline $\begin{array}{l}\text { Realiza } \\
\text { Eventos }\end{array}$ & $\begin{array}{l}\text { Especializou-se em eventos acadêmicos, como congressos, fóruns e outros acon- } \\
\text { tecimentos ligados a universidades. Mantém parceria com grandes instituições da } \\
\text { região, como Univali e Furb, mantendo assim um público cativo. Está no mercado } \\
\text { há doze anos. }\end{array}$ \\
\hline $\begin{array}{l}\text { Claro As- } \\
\text { sessoria de } \\
\text { Eventos }\end{array}$ & $\begin{array}{l}\text { Com apenas dois meses de funcionamento, tem como seu principal sócio um jovem } \\
\text { recém-formado, com muitos contatos em grandes empresas da cidade e região, } \\
\text { além de estar inserido na alta sociedade, fazendo parte de uma das mais tradicionais } \\
\text { famílias da cidade. Assim, já ingressou no mercado 'roubando' uma grande fatia } \\
\text { de público das empresas mais tradicionais. A empresa tem facilidade de acesso ao } \\
\text { mercado de diversas empresas, porém não tem um nicho de mercado definido, o } \\
\text { que pode diminuir sua qualidade e credibilidade no mercado. }\end{array}$ \\
\hline
\end{tabular}

Fonte: Elaborado pelos autores.

Geovan sabe da necessidade de planejamento e gestão na área de marketing para evitar decisões acidentais e informais de acordo com oportunidades e circunstâncias, para tal foi buscar estas empresas que atuam no ramo, para saber como estavam seus posicionamentos no mercado. Esta lista foi feita, pois desde sua origem a Multieventos se utilizava de um marketing que priorizava o boca a boca como meio de venda de seus serviços ao público, porém este meio já não condizia com a vontade dos sócios da empresa de crescer e buscar novos mercados.

\section{ESCOLHENDO OS MELHORES FORNECEDORES E PARCEIROS}

Para o fornecimento de equipamentos eletrônicos e audiovisuais, a referência na cidade é a D2D Equipamentos, empresa com 12 anos de atuação, pioneira na área em Balneário Camboriú, trabalha com aluguéis de equipamentos audiovisuais, como data-show, tela de projeção, flipchart, microfones, caixas de som, mesas de equalização, canhões de luz,b entre outros. Com nome consolidado no mercado, possui grande variedade e quantidade de produtos, suficiente até os dias atuais para atender todos os eventos da cidade, mesmo que simultâneos. Conta em sua equipe com profissionais de suporte técnico para ajudar na montagem, na instalação, na operação, na retirada e no transporte de seus produtos.

Em contato com Felipe, sócio-diretor da empresa, Geovan expôs a expectativa de crescimento da Multieventos e sobre a preocupação na disponibilidade de equipamentos para seus futuros trabalhos. Felipe foi taxativo, informou que no momento não tem interesse em maiores investimentos em seu negócio, que manteria sua política e não poderia dar preferência à Multieventos em detrimento das outras empresas do mercado, mas que por outro lado a D2D sempre atendeu à sua demanda.

Geovan sabia da existência de outras duas empresas do mesmo ramo localizadas no município, a Celsom e a Echos, e decidiu conhecê-las. Na Echos foi atendido por Telma, a proprietária, e 
descobriu uma empresa com dois anos de experiência, lutando por seu espaço no mercado. A Echos possuía em seu catálogo diferentes equipamentos de multimídia, capazes de atender a qualquer tipo de evento. Para Geovan o único contra era que a empresa possuía pouca quantidade para cada aparelho, em aparelhos mais complexos, como caixas de som maiores e projetores de alta resolução, a Echos só possuía uma unidade. A empreendedora comentou com Geovan que havia investido muito, comprando material de primeira qualidade e que também estava disposta a crescer no mercado, assim se propondo a garantir à Multieventos equipamentos sempre que necessário e contratar um profissional somente para o suporte técnico, que não havia na empresa, requisitando, em contrapartida, a garantia de ser a única fornecedora para a agência. Geovan ficou encantado com a proposta, mas pediu a Telma um prazo para pensar e conversar com Léia. Outro fator que impediu de confirmar o negócio foi o preço cobrado pela Echos estar um pouco acima do exercido pela $\mathrm{D} 2 \mathrm{D}$, porém com equipamentos mais novos e modernos.

Na Celsom foi recebido pelo diretor Celso Soares, que já conhecia a Multieventos. Celso apresentou uma empresa sem muitos recursos, com equipamentos já um pouco obsoletos e em pouca quantidade. Contou que seu público era, na maioria, gerentes de eventos da hotelaria local. Porém, o preço praticado pela Celsom estava bem abaixo da Echos e D2D, o que o levou Geovan a considerar a empresa como uma "carta na manga" para eventos nos quais os clientes não disporiam de muitos recursos financeiros.

Na opinião do sócio da Multieventos, era fundamental a confiança em parceiros de outras áreas, como proprietários de espaços para a realização de eventos e fornecedores de alimentos e bebidas, entre outros.

Geovan dirigiu-se ao B.C. HALL, único espaço na cidade que trabalha exclusivamente com aluguel de salas para organização de eventos. Em uma visita, acompanhado pela gerente do local, percorreu um moderno espaço de $2.500 \mathrm{~m}^{2}$ que poderia ser utilizado como um grande salão ou dividido em até sete salas moduláveis. Com oito anos de atuação no mercado e pela qualidade dos espaços disponibilizados, é referência na cidade.

Manuela, a gerente do local, ficou entusiasmada com a expectativa de crescimento por parte dos dois jovens da Multieventos. Pelo feedback que recebia de seus clientes, a Multieventos tinha bom serviço em seu segmento na cidade. Ela informou que há alguns anos realizou ações visando agregar valor e maximizar seus ganhos, entre elas a compra de equipamentos audiovisuais próprios e a contratação de funcionários para os serviços de A\&B. Mas que, infelizmente, teve que se desfazer de tudo, por ter prejuízos com roubos de seus equipamentos e por não conseguir manter a qualidade esperada nos serviços de alimentação, voltando a operar, nos últimos três anos, somente com o aluguel dos espaços.

O B.C. HALL sempre havia sido a primeira opção em salas para Léia e Geovan, quase sempre aceita por seus clientes, era uma escolha prática e versátil, sempre com bons serviços, mas estava cada vez mais difícil alinhar datas. Manuela garantiu que, enquanto a Multieventos estivesse em seu processo de crescimento, tentaria manter os mesmos preços praticados, mas que em relação às datas, nada poderia fazer.

Para se antecipar a uma possível situação problemática, resolveu estreitar contatos com dois dos melhores hotéis da cidade. Geovan sabia das dificuldades de se trabalhar com hotéis, por possuírem regras próprias para organizações de eventos, como exclusividade na contratação de serviços de $A \& B$, pouca autonomia para montagem dos espaços, preços muito mais elevados e horários mais disputados, por competir pelos locais com organizações de festas sociais. O Astor Plaza, localizado na parte central da Avenida Atlântica, tem o centro de eventos situado nos últimos três andares do prédio, com a fachada toda de vidro, possui uma magnífica vista para a praia central e a Ilha das Cabras, sendo atualmente o local preferido pela alta sociedade para a realização de seus eventos.

Lá foi atendido pelo gerente de eventos do hotel, que informou que as empresas que mais trabalham com ele são a Claro e a M\&G, mas que o hotel possuía interesse em atender mais ao público empresarial. As salas, apesar de novas e bonitas, eram muito grandes e pouco funcionais o que, para Geovan, atrapalhava um pouco a realização de eventos em seu segmento, mas que, se atuassem com grandes eventos empresariais, seria uma alternativa interessante. Os preços praticados pelo hotel eram exorbitantes e nem os descontos concedidos em alimentação aliviariam o valor total do evento. Para o gerente do local os preços estavam sendo praticados de forma 
justa, pois já não existia agenda para os finais de semana no prazo de um ano e só poderiam ser agendados novos eventos havendo a desistência de outros.

O outro hotel, o Village, localizado na barra norte da cidade, possui um centro de eventos anexo ao prédio principal. A Multieventos já havia realizado eventos lá e Geovan sabia que a qualidade do serviço prestado aos clientes de eventos não era a mesma dispensada aos hóspedes. Mas como já havia muito tempo desde o último contrato acertado, achou que era hora de rever o espaço. Quando chegou, descobriu que o responsável pelo setor era Marcos, o mesmo de antigamente, que demonstrava a já tradicional má vontade em atender aos seus clientes. Marcos o levou para visitar os espaços, que eram exatamente iguais aos que Geovan havia encontrado na última vez que esteve lá. O gerente comentou que os preços haviam aumentado devido à procura pelo local, e que, a partir daquele ano, os eventos eram agendados com antecedência mínima de seis meses.

Feitas as visitas, Geovan encontrou-se com Léia, relatou os fatos e o medo de não conseguirem mais espaços. Léia tinha a certeza de que o mercado estava assim para todos e tinha a confiança de que, sempre que precisassem, encontrariam locais, mesmo que tivessem que pagar mais por isto. Ainda havia partes sobre o mercado que precisavam ser expandidas pela Multieventos. Tão importante quanto espaços e equipamentos audiovisuais, eram as empresas fornecedoras de alimentos e bebidas, responsáveis pela organização de coffee breaks, cafés da manhã, almoços e jantares e aquelas que disponibilizam funcionários para recepção, segurança e serviços de A\&B.

A Confeitaria Armelin é a empresa que a Multieventos sempre trabalhou sem problemas com prazo ou qualidade dos produtos. Porém só havia necessitado de coffee breaks até então, e a preocupação de Geovan estava no atendimento e na confiabilidade de outros serviços. A proprietária da Armelin, Lurdes, já sua amiga após os dois anos de parceria, tranquilizou-o, afirmou que estava pensando também em expandir sua empresa e que esta seria uma ótima oportunidade para ambos crescerem. Lurdes ponderou que, neste primeiro período de experiência e com os anos de trabalho conjunto, poderia oferecer à Multieventos um desconto sobre o preço que estava planejando cobrar.

Geovan achou estranho e foi pesquisar o que estava acontecendo com o mercado. Nesta procura descobriu cinco novas empresas no ramo, todas com preços tão baixos quanto a Armelin e oferecendo também os melhores serviços e produtos a Geovan, que permaneceu com o contato de todos, prometendo dar uma oportunidade a cada uma de mostrar seus diferenciais.

Para a terceirização de mão de obra só havia uma empresa na cidade, a Terceiriza, que possui em seu cast um grande número de profissionais de limpeza, seguranças, garçons e recepcionistas. Seu proprietário é Cláudio Silva, um sujeito arrogante com quem é muito difícil de negociar. Cláudio garantiu que estaria pronto para cobrir qualquer aumento na demanda enquanto não precisasse contratar mais trabalhadores, e que, garantiu, não tencionava fazer tão cedo. Informou também que não poderia fazer um desconto a Multieventos durante o seu processo de crescimento: pois seu preço era aquele e qualquer outro praticado abaixo acarretaria prejuízos para sua empresa. Coube a Geovan aceitar estas condições impostas.

\section{INVESTIR PARA CRESCER}

Léia passou o mês de janeiro realizando uma completa análise da saúde financeira da empresa. Contatou com diversas financiadoras e bancos para buscar um financiamento para a expansão da Multieventos. Tomando por base as reuniões realizadas com Geovan, ela chegou ao montante de $\mathrm{R} \$ 45.000,00$, necessário para o primeiro passo na expansão da Multieventos. Com este valor eles montariam um pequeno escritório, investiriam em novos computadores, contratariam um funcionário para auxiliá-los e, seu principal investimento seria no marketing e na divulgação da empresa.

A empresa conta atualmente com um valor em caixa de $\mathrm{R} \$ 10.000,00$ (caderneta de poupança) que, por sugestão de Léia, deverá ficar reservado para despesas de emergência. As quatro opções de financiamento levantadas por Léia no mercado são as apresentadas no Quadro 2. 


\section{Turismō}

Quadro 2: Opções de financiamento

\begin{tabular}{|c|c|}
\hline Banco Mundial & Financiadora Novo Crédito \\
\hline Valor do empréstimo: $\mathrm{R} \$ 45.000,00$ & Valor do empréstimo: $\mathrm{R} \$ 45.000,00$ \\
\hline Prazo de pagamento: 48 parcelas & Prazo de pagamento: 36 parcelas \\
\hline Taxa de juros $=3,5 \%$ a.m. & Taxa de juros $=2,5 \%$ a.m. \\
\hline Prazo de carência: não tem & Prazo de carência: 6 meses \\
\hline Financiadora Real & BanCoop \\
\hline Valor do empréstimo: $\mathrm{R} \$ 45.000,00$ & Valor do empréstimo: $\mathrm{R} \$ 45.000,00$ \\
\hline Prazo de pagamento: 48 parcelas & Prazo de pagamento: 30 parcelas \\
\hline Taxa de juros $=3,5 \%$ a.m. & Taxa de juros $=2 \%$ a.m. \\
\hline Prazo de carência: 6 meses & Prazo de carência: 3 meses \\
\hline
\end{tabular}

Fonte: Elaborado pelos autores.

Com base nestes dados e nos fluxos de caixa dos últimos anos, a sócia também elaborou um orçamento de caixa que permitiu calcular e visualizar a viabilidade do investimento. Léia tomou cuidado em montar um fluxo o mais próximo possível da realidade, calculando o orçamento do momento de abertura até os próximos 5 anos. Na abertura, calculou R $\$ 45.000,00$; no ano 1; $\mathrm{R} \$ 12.000,00$; no ano 2, R\$13.800,00; no ano 3, R\$15.800,00; no ano 4, R\$16.800,00; e no ano 5, R\$17.500,00.

Com sua experiência na área financeira, sabia, porém, que poderiam acontecer imprevistos. Assim, ela usou este cenário como o fluxo mais próximo possível da realidade e a partir deste pôde elaborar outros fluxos mais conservadores.

\section{QUAL DECISÃO TOMAR?}

Após duas semanas de árduo trabalho, Léia e Geovan elaboraram relatórios com as informações levantadas e necessárias para a continuação do planejamento e refinamento do plano de negócios de expansão. E chegou a hora da reunião para a tomada de decisão final sobre o rumo da empresa. Não seriam decisões fáceis, mas sabiam que a expansão era necessária para o sucesso da empresa e para sua satisfação pessoal.

NOTAS TÉCNICAS

\section{FONTE DE DADOS}

Este caso retrata a história de uma empresa fictícia, sendo os dados numéricos também fictícios. A elaboração do trabalho foi efetuada com o auxílio de bibliografias na área de marketing, finanças, empreendedorismo e com a experiência no ramo dos autores do trabalho.

\section{QUESTÕES PARA DISCUSSÃO}

1) Analisando o mercado da cidade de Balneário Camboriú, quais poderiam ser as opções de expansão do negócio?

2) Quais os diferenciais que a empresa poderia propor aos clientes para obter vantagens competitivas em seu negócio? 
3) Analise o perfil empreendedor dos sócios, apontando suas características empreendedoras.

4) Utilize as ferramentas fornecidas no caso para conhecer mais aprofundadamente a Multieventos e o mercado no qual ela está inserida. Para isto, faça uma análise SWOT e a análise das cinco forças de Porter com base nos dados oferecidos e em seu conhecimento da área.

5) Indique qual a melhor opção de financiamento para a empresa entre as 4 opções apresentadas no relatório financeiro, levando em consideração que a empresa pode pagar uma parcela mensal de até $\mathrm{R} \$ 2.000,00$ e que o prazo para o início das atividades que irão gerar o aumento do faturamento é de 5 meses.

6) Após estudos de mercado, operação e investimento, Léia elaborou um quadro (Quadro 2) com entradas anuais o mais próximas da realidade possível. Elabore um fluxo de caixa real e outro mais conservador, diminuindo em $10 \%$ o valor das entradas em cada ano. Após, calcule a VPL, TIR, payback e payback descontado para os dois fluxos, argumentando se é viável o projeto de expansão.

\section{REVISÃO DE LITERATURA}

\section{EMPREENDEDORISMO: CONCEITOS E CARACTERÍSTICAS EMPREENDEDORAS}

De acordo com o Serviço Brasileiro de Apoio à Micro e Pequenas empresas (SEBRAE) apud Dornelas (2007), existe um conjunto de características de empreendedores mais utilizado no Brasil, apresentado no Quadro 3.

Quadro 3: Características dos empreendedores de sucesso utilizadas pelo SEBRAE

\begin{tabular}{|l|l|}
\hline Grupos & Características \\
\hline Relacionadas à realização & $\begin{array}{l}\text { Busca de oportunidade e iniciativa; correr riscos calculados; exigir } \\
\text { qualidade e eficiência; persistência e comprometimento. Característi- } \\
\text { cas ligadas à busca pela realização e à realização pessoal do empreend- } \\
\text { edor. Formas e meios de agir para atingir a realização pessoal. }\end{array}$ \\
\hline Relacionadas ao planejamento & $\begin{array}{l}\text { Busca de informações; estabelecimento de metas; planejamento e } \\
\text { monitoramento sistemático. Características ligadas à metodologia de } \\
\text { trabalho do empreendedor, a forma de ação que este deve seguir para } \\
\text { facilitar o sucesso de seu negócio. }\end{array}$ \\
\hline Relacionadas ao poder & $\begin{array}{l}\text { Persuasão e redes de contatos; independência e autoconfiança. Car- } \\
\text { acterísticas que indicam qualidades que o empreendedor necessita e } \\
\text { formas de ação importantes para o desempenho da função. }\end{array}$ \\
\hline Fonte: Dornelas (2007, p. 8).
\end{tabular}

Fonte: Dornelas (2007, p. 8).

Paiva Jr. e Cordeiro (2002) também concordam que ainda não existe um consenso absoluto sobre o conceito de empreendedorismo, porém existe consenso de que os empreendedores exercem a função social de identificar oportunidades e convertê-las em valores econômicos. Para Dornelas (2007), apesar de a tentativa de entender quem é o empreendedor ser antiga e de existirem muitas revisões sobre o assunto, não há muitas variações nas características dos empreendedores ao longo das últimas décadas, embora alguns atributos sejam mais citados do que outros.

De Mori (1998) apresenta um resumo das características dos empreendedores de sucesso. Seus estudos resultaram nas seguintes características (Quadro 4): 
Quadro 4: Características dos empreendedores de sucesso

\begin{tabular}{|l|l|}
\hline Característica & Especificação \\
\hline Necessidades & $\begin{array}{l}\text { Aprovação; Independência; Desenvolvimento pessoal; Segurança; Autorrealiza- } \\
\text { ção. }\end{array}$ \\
\hline Habilidades & $\begin{array}{l}\text { Aspectos técnicos relacionados com o negócio; Experiência na área comercial; } \\
\text { Escolaridade; Experiência em empresas; Formação complementar; Vivência com } \\
\text { situações novas. }\end{array}$ \\
\hline Valores & $\begin{array}{l}\text { Identificação de novas oportunidades; Valoração de oportunidades e pensamento } \\
\text { criativo; Comunicação persuasiva; Negociação; Aquisição de informações; Resolução }\end{array}$ \\
\hline Existenciais; Estéticos; Intelectuais; Morais; Religiosos.
\end{tabular}

Fonte: De Mori (1998, p. 40).

Em relação às Necessidades, para De Mori (1998), o futuro empreendedor, para se tornar um empreendedor de sucesso, precisa ter fortes anseios ao investir; aprovação da sociedade, considerada a imagem do empreendedor junto ao público; possibilidade da independência financeira; desenvolvimento pessoal; e melhora do empreendedor como pessoa, por meio de estudo e de conhecimento com o tempo de trabalho no mercado onde atua. Segurança decorrente do sucesso de seu negócio e desejo por autorrealização fazem parte do perfil ideal de empreendedores.

De Mori (1998) salienta que somente o conhecimento técnico ou científico não é garantia para o empreendedor atingir êxito em seu negócio. Estes dois conhecimentos devem ser alinhados e acrescidos ainda de formação complementar e de atualização, passagem por empresas do ramo e coragem de enfrentar situações novas. Para o autor, o empreendedor de sucesso deve ter, entre suas habilidades, a identificação de novas possibilidades, normalmente vinda por meio de conhecimento de mercado, porém, esta identificação somente é válida quando se valoriza esta nova oportunidade e se decide investir nela. Outro ponto adotado pelo autor como importante habilidade do empreendedor de sucesso é relacionado à comunicação e à capacidade de negociação, seja com clientes, fornecedores ou colaboradores.

Por último, De Mori (1998) acredita que ter valores é também importante para o empreendedor de sucesso, estes valores, para o autor, não são necessariamente religiosos, podem ser morais, intelectuais, estéticos ou existenciais, porém, independente do escolhido, deve ser buscado sempre, norteando as ações do empreendedor.

Atualmente a sociedade vive num ritmo acelerado de mudanças, num mundo em transformação contínua, com alterações de hábitos de consumo, mudanças demográficas e surgimento de novas tecnologias, segundo Gimenez e Gimenez (2010). A criação de novas empresas está associada com condições de incerteza, assim, o ato de empreender ocorre de forma natural em indivíduos que aceitam a propensão ao risco e aceitam situações de incerteza. Outro fator importante é a postura estratégica ao se criar um novo negócio: isto envolve a capacidade de pensar a longo prazo, monitorar o ambiente econômico e social onde a empresa está inserida e a realização de planejamento sistemático e formal (GIMENEZ; GIMENEZ, 2010).

Neste contexto de economia globalizada, Pereira (2005) argumenta que são necessárias outras atitudes empreendedoras, como a oferta de produtos e serviços com altos índices de qualidade, foco no cliente, na personalização, na ética, na responsabilidade ambiental e social e no uso de tecnológica de ponta. Os desafios e as perspectivas que o novo contexto mundial oferece aos empreendedores são grandes, por isso o planejamento, a busca por informações e a atualização constante são imprescindíveis para um negócio de sucesso.

Outro fator importante é a elaboração de um plano de negócios. Não se pode negligenciar o estágio de planejamento, ou seja, deixar de elaborar um plano por escrito para saber da viabilidade do projeto (LONGENECKER; MOORE; PETTY, 1997). Isso porque distinguir uma oportunidade e ter uma ideia de como satisfazê-la não são suficientes para dar início a um novo negócio (STONER; 
FREEMAN, 1995). Em resumo, o plano de negócios é, segundo Stoner e Freeman (1995, p. 122), um "documento formal contendo uma declaração de missão, a descrição dos bens e serviços da empresa, uma análise de mercado, projeções financeiras e uma descrição das estratégias da direção para alcançar os objetivos da empresa".

Um plano de negócios bem elaborado pode trazer diversos benefícios ao novo empreendedor. Primeiramente, ele possibilita ao empreendedor captar as variáveis importantes de sucesso ou fracasso e ajuda a enfocar nas questões e atividades mais importantes que precisam ser examinadas. Outro benefício é forçar o empreendedor a exercitar a disciplina necessária aos bons gerentes. Se bem concebido, o plano de negócios é a base para comunicar a missão da empresa ao público interno e externo, e se torna um alicerce seguro para operar os negócios.

Internamente, o plano de negócios serve para a comunicação com os empregados da empresa, inclusive como ferramenta para recrutar pessoas-chave. Externamente, o uso do plano se amplia para usuários diversos, sendo o "cartão de visitas" do empreendedor. Os investidores são os usuários primários do plano de negócios. É com ele que o empreendedor irá recorrer a banqueiros, investidores individuais, capitalistas de risco e outras fontes para levantar fundos financeiros e iniciar o negócio. Além disso, o plano também pode ser útil para o bom relacionamento em bancos e para ganhar a confiança de fornecedores e clientes (LONGENECKER; MOORE; PETTY, 1997).

\section{MARKETING: ANALISAR O MERCADO PARA GARANTIR O SUCESSO NAS VENDAS}

Segundo Walker (1985), bens e serviços se distinguem na forma de trabalho e no seu produto. Um bem é um objeto material produzido pelo trabalho humano e, por outro lado, um trabalho em serviços é um trabalho que não toma a forma de um produto material, portanto é normalmente não reproduzível por outros trabalhadores e envolve uma transação única entre produtor e consumidor. Cobra (1986) expôs as diferenças entre produtos e serviços (Quadro 5)..

Com base nestas diferenças foi criado o marketing de serviços, conceituado também por Cobra (1986, p. 381) como "uma disciplina que procura estudar os fenômenos e os fatos que ocorrem na venda dos serviços", e o próprio autor complementa dizendo que "o objetivo do marketing de serviços deve ser proporcionar alvos para o direcionamento e controle das estratégias de marketing, de forma que os objetivos de marketing são submetas para o cumprimento das metas gerais da empresa" (COBRA, 1986, p. 400). Segundo Lima Filho (2001), marketing de serviços consiste em "atividades operacionais destinadas a investigar, obter e servir a demanda por assistência profissional. Nestas atividades incluem-se as tarefas de desenvolvimento e promoção de serviços pessoais e comunitários." (LIMA FILHO, 2001, p.1).

Para Kotler, dez problemas característicos diferenciam o marketing de serviços do marketing tradicional, são eles: a responsabilidade de terceiros, incerteza do cliente, importância a experiência, limitações de diferenciação, manutenção do controle de qualidade, transformação de realizadores em vendedores, reservar tempo dos profissionais para o marketing, pressão para reagir em vez de se antecipar, visões conflitantes em relação à propaganda e conhecimentos limitados de marketing. Para o autor estes problemas dificultam o trabalho no setor.

A análise SWOT é uma ferramenta de gestão utilizada para planejamento de marketing, com ela é possível fazer uma análise dos ambientes interno e externo de uma organização, buscando suas forças (strenghts), fraquezas (weaknesses), oportunidades (opportunities) e ameaças (threats). A aplicação da análise SWOT se sustenta por ter seu mérito reconhecido por ser uma ferramenta líder para análise estratégica, principalmente por sua simplicidade e clareza (COMAN \& RONEN, 2009).

Segundo Tonini, Spínola e Laurindo (2007), esta análise é dividida em duas partes, o ambiente externo à organização (oportunidades e ameaças) e o ambiente interno (forças e fraquezas). Para os autores, o ambiente externo está totalmente fora de controle da organização, este ambiente age de maneira homogênea para todas as organizações atuantes no mesmo mercado e na mesma região, representando desta forma ameaças e oportunidades para todos. Entre estas oportunidades e ameaças podem ser encontradas aumento da concorrência, aumento e diferenciação do públicoalvo, novos regulamentos econômicos, questões legais, entre outros. $\mathrm{O}$ ambiente interno, por 
outro lado, é aquele que pode ser controlado pela empresa, sendo assim diretamente sensível às estratégias formuladas pela organização; dentro dos tópicos abordados nos pontos fortes e fracos, estão a qualificação dos colaboradores, o contato com os fornecedores, as questões burocráticas e de trânsito dentro das organizações.

Para Tarapanoff, a maneira mais eficaz de se utilizar esta análise é "criar uma escala onde cada uma destas variáveis é avaliada em relação aos objetivos da organização. Costuma-se classificá-la como: força importante, força sem importância, neutralidade, fraqueza importante ou fraqueza sem importância. Como a organização raramente pode investir em todas as áreas ao mesmo tempo, os itens fraquezas importantes e forças importantes devem ser priorizados ao se traçar estratégias de marketing e receber orçamento" (TARAPANOFF, 2001, p.31).

O primeiro passo para a confecção desta análise é desenhar em uma folha um cruzamento com quatro setores, um para cada grupo. Após, relacionam-se os itens nos grupos correspondentes (forças, fraquezas, oportunidades e ameaças). É melhor limitar esta listagem a um máximo de dez itens por grupo, evitando generalizações (JOHNSON et al., 1989 in BALAMULARIKRISNHA \& DUGGER, 1995, p. 6). A análise pode ser feita individualmente pelo administrador ou em grupos, esta última técnica é mais efetiva, pois fornece estrutura, objetividade, clareza e foco nas discussões sobre estratégias, porém pode ser fortemente influenciada por politicagem ou personalidades (BALAMULARIKRISNHA \& DUGGER, 1995, p. 6).

Michael Porter, em seu livro Estratégia Competitiva: Técnicas para Análise de Indústrias e da Concorrência, propõe um modelo de análise da estrutura competitiva, levando em consideração diferentes forças de caráter estrutural básico que atuam nas fronteiras de uma empresa e tendo como objetivo explicar as razões para o grau de atratividade e uma indústria a longo prazo, que resultaria da ação em conjunto de cinco fatores: novos entrantes, produtos substitutos, poder de barganha dos fornecedores, poder de barganha dos clientes e rivalidade entre concorrentes. Para o autor, os novos entrantes seriam empresas do mesmo ramo, concorrentes diretos na área de atuação da empresa. Os produtos substitutos são aquelas empresas que concorrem em somente um ou outro ponto da atividade. O poder de barganha dos fornecedores pode ser medido por meio da quantidade de fornecedores existentes, do tipo de trabalho e qualidade realizada por estes, da quantidade de concorrentes existentes e da necessidade destes concorrentes de possuírem os mesmos produtos ao mesmo tempo. O poder de barganha dos clientes é medido também pela quantidade de concorrentes, ele considera até que ponto o cliente pode negociar com diferentes empresas para alcançar o valor desejado. Por último, a rivalidade entre os concorrentes é fruto destas demais análises, quanto mais acirradas forem as disputas por fornecedores, por clientes, e quantos mais concorrentes existirem, maior será esta rivalidade.

Segundo o autor (1990), as cinco forças podem ameaçar a sustentabilidade do desempenho industrial. Assim, esse conjunto de forças pode ser avaliado como uma ameaça e, a partir de sua identificação, pode-se construir uma matriz de oportunidades para a empresa.

Na concepção de Grundy, o modelo das 5 forças de Porter é um conceito de vital importância e um de seus maiores méritos é merecer atenção de todos os executivos seniores (GRUNDY, 2006). Michael Porter defende que uma empresa, para melhor competir num determinado segmento estratégico, ou indústria, deve decidir a sua estratégia, com base no conhecimento da estrutura do sector de atividade em que compete e na perfeita identificação dos clientes alvo (TEIXEIRA, 2005).

\section{ANÁLISE DE INVESTIMENTOS: O NEGÓCIO É VIÁVEL?}

Para uma análise de investimentos bem-sucedidos, é imprescindível que haja três pontos: estratégia da empresa, suas decisões de investimentos e de financiamento e suas operações. A estratégia compreende os meios para atingir os objetivos. A empresa identifica as oportunidades e os riscos oferecidos pelo ambiente externo, definindo assim o que fazer, o seu público-alvo e também a sua área de atuação geográfica, ajustando assim sua estrutura organizacional para assim operacionalizar o que definiu inicialmente.

Para Silva (2005), a realização de uma análise financeira em uma empresa basicamente envolve as seguintes atividades: coletar demonstrações contábeis e outras informações relativas ao mercado 
de atuação da empresa e dos seus produtos; conferir consiste em uma pré-análise para verificar se as informações estão completas e confiáveis; preparar a reclassificação das demonstrações contábeis para adequá-las aos padrões internos da instituição que vai efetuar a análise, tampouco a organização de todo o material de leitura e demais dados disponíveis para a análise; processar as informações e a missão de relatórios no formato interno da instituição, entre eles o balanço patrimonial, demonstração do resultado do exercício, demonstração de fluxo de caixa, compatibilidade do CPL; analisar todas as informações disponíveis, principalmente dos relatórios e dos indicadores já obtidos, compreendendo a consistência das informações, a observação das tendências apresentadas pelos números e todas as demais conclusões que possam ser extraídas do processo e, finalmente, a conclusão que é considerada a mais importante consiste em identificar, ordenar, destacar e escrever sobre os principais pontos e recomendações acerca da empresa.

Dentro de uma análise de investimentos, possuem-se algumas técnicas para avaliação de investimento de capital, dentro delas o valor presente líquido (VPL), também conhecido por valor atual líquido (VAL), que é um método bastante difundido na área de tomada de decisão sobre investimento, por tratar-se de um método de fácil elaboração. Segundo Fleischer (1973), a principal característica do método do Valor Presente Líquido "é o desconto para o valor presente de todos os fluxos de caixa esperados como resultado de uma decisão de investimento". A segunda técnica é a Taxa Interna de retorno (TIR); nesse, não há solução algébrica simples para equação, portanto para calcular a TIR aplica-se o processo de tentativa e erro, isto implica a obtenção de um valor positivo e outro negativo, correspondente às duas taxas de juros tomadas arbitrariamente. Oliveira (1982) define taxa interna de retorno como aquela que torna o valor dos lucros futuros iguais ao valor dos gastos realizados. E ainda de acordo com Fleischer (1973), a taxa interna de retorno de um investimento é a taxa de juros que o valor presente dos recebimentos do projeto é igual ao valor presente dos desembolsos. Assim, o critério para a decisão de investimento com base na TIR é aceitar um investimento se o custo de hora do capital for menor do que a taxa interna de retorno.

Já o Pay Back é um método bastante utilizado para medir a atratividade de um investimento, levando em consideração o seu maior objetivo "o lucro", não o tempo de retorno do capital inicialmente investido. Uma das suas principais características é a desconsideração de qualquer fato além do período final em que o capital foi readquirido. Mesmo tendo essa característica, ele tem papel fundamental de fornecer informações de interesse, principalmente quando o futuro é incerto, e o interesse em recuperar o investimento inicial é o mais rápido possível.

Uma análise de investimentos não pode ser limitada apenas aos indicadores de natureza financeira, pois há uma série de fatores que, mesmo não podendo ser chamados de financeiros, causam impacto na saúde financeira da empresa.

\section{ANÁLISE DAS QUESTÕES}

\section{Questão 1:}

Balneário Camboriú é uma cidade em crescimento constante, recebe um grande fluxo de turistas e também investidores. O mercado imobiliário está em alta na cidade, com construções de inúmeros prédios residenciais para a população de classe alta. Um ótimo nicho para expansão dos negócios seria trabalhar com eventos de lançamento e inauguração de prédios. Os clientes seriam as diversas construtoras e as imobiliárias da cidade. Nesta mesma linha, poderiam também atender outras cidades da região que estão se desenvolvendo muito no setor imobiliário, como Itajaí, Itapema, Porto Belo e Bombinhas.

\section{Questão 2:}

Com a globalização, clientes estão cada vez mais exigentes e procuram por diferenciais nos produtos e nos serviços. A Multieventos poderia se diferenciar das demais empresas de eventos oferecendo as seguintes opções aos seus clientes:

- Atendimento em outras línguas;

- Trabalho com equipamentos audiovisuais e sonorização de última geração;

- Responsabilidade social e ambiental, trabalhando com fornecedores social e ambientalmente corretos; 
- Parcerias apenas com os fornecedores mais qualificados;

- Capacitação contínua aos funcionários, aliando motivação e criatividade;

- Estabelecimento de vantagens e benefícios exclusivos aos clientes;

- Valorização do capital intelectual, com o gerenciamento dos talentos existentes.

\section{Questão 3:}

Por meio do estudo de caso da Multieventos, podem-se verificar as principais características empreendedoras e as atitudes de seus sócios, Léia e Geovan, apresentadas no Quadro 6.

Os sócios da empresa Multieventos possuem um perfil e características peculiares aos empreendedores. Percebe-se que algumas características são peculiares de cada um, porém grande parte delas se repete nos dois sócios. Conclui-se que este perfil foi decisivo para o sucesso e crescimento da empresa.

Quadro 6 - Características empreendedoras e atitudes dos sócios da empresa

\begin{tabular}{|c|c|}
\hline Características empreendedoras & Atitudes \\
\hline $\begin{array}{l}\text { Autorrealização/Independência } \\
\text { Iniciativa } \\
\text { Busca por novas oportunidades }\end{array}$ & Sonho de ter o próprio negócio \\
\hline Experiência e formação & $\begin{array}{l}\text { Formação superior; Estágios e emprego na área } \\
\text { Cursos complementares no SEBRAE }\end{array}$ \\
\hline Planejamento & $\begin{array}{l}\text { Elaboração de um plano de negócios } \\
\text { Balanço anual com planejamento de estratégias e ações. }\end{array}$ \\
\hline Criatividade & Característica de Léia ao elaborar o material de divulgação \\
\hline Persuasão/Rede de contatos & Características de Geovan no contato com potenciais clientes \\
\hline $\begin{array}{l}\text { Serviços de qualidade } \\
\text { Seriedade/Resolução de problemas }\end{array}$ & $\begin{array}{l}\text { Escolha minuciosa dos fornecedores } \\
\text { Atendimento rápido e eficaz ao cliente }\end{array}$ \\
\hline $\begin{array}{l}\text { Ascensão profissional } \\
\text { Inovação }\end{array}$ & Sonho de expandir o negócio \\
\hline Assumir riscos calculados & Financiamento para expansão \\
\hline $\begin{array}{l}\text { Responsabilidade social e ambiental } \\
\text { Ética/Seriedade }\end{array}$ & $\begin{array}{l}\text { Profissionalismo e diferenciação na expansão do negócio } \\
\text { Fornecedores ambiental e socialmente corretos }\end{array}$ \\
\hline Uso de tecnologia de ponta & Procura pelos melhores fornecedores \\
\hline
\end{tabular}

Fonte: Elaborado pelos autores.

\section{Questão 4:}

\section{Análise das 5 forças de Porter:}

\section{Ameaça de Novos Entrantes:}

Por se tratar de um serviço com pouca dificuldade de acesso e de relativo baixo custo inicial, é de se supor que, a partir do sucesso das empresas já atuantes no mercado, novos investidores entrarão neste ramo. Os hotéis também podem passar a atuar na organização dos eventos, e não só na comercialização de espaços para o mesmo, aumentando assim sua participação no mercado. 
Ameaça de Produtos Substitutos:

O aumento da procura e da exigência de serviços de qualidade no setor de eventos em Balneário Camboriú pode levar as empresas, tradicionais clientes dos organizadores de eventos, a ter, em seus próprios quadros funcionais, colaboradores capacitados a tal tarefa, o que acarretaria uma diminuição do mercado total de clientes.

Poder de Barganha dos Clientes:

Por existir diversas empresas do ramo na cidade, os clientes têm muito poder de barganha, tentando ao máximo a redução de preços e a alta qualidade do serviço.

Poder de Barganha dos Fornecedores:

Alguns fornecedores detêm alto poder de barganha, caso da Terceiriza, empresa de terceirização de pessoal, por ser a única de seu setor na região e das empresas de aluguel de equipamentos eletrônicos. Já os fornecedores de alimentos e bebidas têm pouco poder de barganha, pois já existem diversas empresas neste ramo que podem ser contratadas. Por fim, a D2D equipamentos tem cada vez menos poder de barganha, pois suas concorrentes estão aumentando seus espaços no mercado.

Rivalidade entre os Concorrentes: Rivalidade moderada entre os concorrentes do município por terem públicos-alvo diferentes, porém esta concorrência obriga a Multieventos a planejar envolvendo preço, propaganda, melhora nos serviços oferecidos, procura sempre por maior qualidade dos fornecedores, entre outros.

\section{Análise SWOT:}

Quadro 7 - Análise SWOT.

\begin{tabular}{|l|l|}
\hline & Oportunidades: \\
Ameaças: & - Acréscimo de usuários; \\
- Acirramento da concorrência; & - Fidelização de clientes; \\
- Desregulamentação econômica; & - Novos públicos-alvo; \\
- Marketing "agressivo" da concorrência. & - Maior procura na área; \\
& - Consolidação do nome. \\
\hline Pontos Fortes: & \\
- Fornecedores fidelizados; & Pontos Fracos: \\
- Fornecedores capacitados; & - Problemas internos de gestão; \\
- Potencial de crescimento; & - Baixa profissionalização; \\
- Grande procura do mercado; & - Poucos fornecedores na região; \\
- Público-alvo diferente de seus concorrentes. & - Difícil negociação com alguns fornecedores. \\
\hline Fonte: Elaborado pelos autores. & \\
\hline
\end{tabular}

\section{Questão 6:}

Como observado no Quadro 8, a opção do Banco Mundial é a proposta com a menor parcela mensal, porém apresenta uma das mais altas taxas de todas as propostas apresentadas e não possui prazo de carência. A proposta da Financiadora Real também não é adequada para a Multieventos, pois, apesar de ter 6 meses de carência, também apresenta uma das mais altas taxas e o valor da parcela é superior a possibilidade de pagamento da Multieventos. 
Quadro 8 - Alternativas de financiamento

\begin{tabular}{|c|c|}
\hline \multicolumn{2}{|l|}{$\begin{array}{l}\text { Banco Mundial } \\
\text { PV }=45.000,00 \\
n=48 \text { parcelas } \\
\mathrm{i}=3,5 \% \text { a.m. } \\
\text { PMT }=1.948,79\end{array}$} \\
\hline Financiadora Novo Crédito & Trabalhar carência \\
\hline$P V=45.000,00$ & $\mathrm{n}=5$ meses (modo END) \\
\hline $\mathrm{n}=36$ parcelas & $\mathrm{FV}=50.913,37$ \\
\hline $\mathrm{i}=2,5 \%$ a.m & Cálculo da prestação \\
\hline Carência $=6$ meses & $\mathrm{PV}=50.913,37 / \mathrm{PMT}=2.161,35$ \\
\hline Financiadora Real & Trabalhar carência \\
\hline$P V=45.000,00$ & $\mathrm{n}=5$ meses (modo END) \\
\hline $\mathrm{n}=48$ parcelas & $F V=53.445,88$ \\
\hline $\mathrm{i}=3,5 \%$ a.m & Cálculo da prestação \\
\hline Carência $=6$ meses & $\mathrm{PV}=53.445,88 / \mathrm{PMT}=1.924,37$ \\
\hline BanCoop & Trabalhar carência \\
\hline$P V=45.000,00$ & $\mathrm{n}=2$ meses (modo END) \\
\hline $\mathrm{n}=30$ parcelas & $\mathrm{FV}=46.818,00$ \\
\hline $\mathrm{i}=2 \%$ a.m & Cálculo da prestação \\
\hline Carência $=3$ meses & $\mathrm{PV}=46.818,00 / \mathrm{PMT}=2.090,42$ \\
\hline
\end{tabular}

Fonte: Elaborado pelos autores.

A escolha do financiamento deverá ficar entre a Financiadora Novo Crédito e o Bancoop. A financiadora Novo Crédito tem uma parcela um pouco superior, porém oferece carência de seis meses. O BanCoop tem uma parcela menor, porém tem apenas 3 meses de carência. Cabe aos sócios rever as opções para verificar qual melhor se adéqua às possibilidades de sua empresa.

\section{Questão 7:}

Fluxo de caixa real:

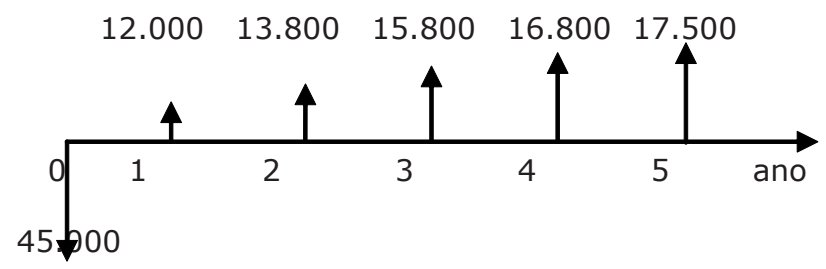


Fluxo de caixa conservador:

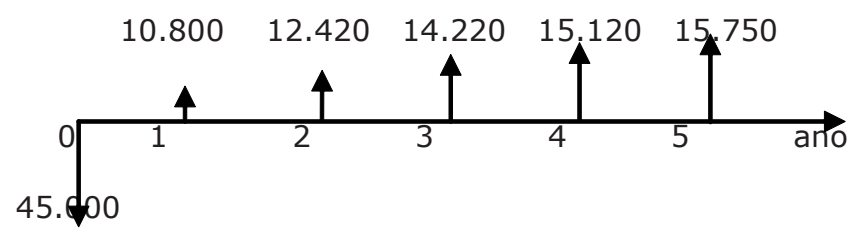

Quadro 9 - Demonstrativo de Fluxos

\begin{tabular}{|l|l|l|}
\hline Anos & Fluxo Real & Fluxo Conservador \\
\hline 0 & $-\mathrm{R} \$ 45.000,00$ & $-\mathrm{R} \$ 45.000,00$ \\
\hline 1 & $\mathrm{R} \$ 12.000,00$ & $\mathrm{R} \$ 10.800,00$ \\
\hline 2 & $\mathrm{R} \$ 13.800,00$ & $\mathrm{R} \$ 12.420,00$ \\
\hline 3 & $\mathrm{R} \$ 15.800,00$ & $\mathrm{R} \$ 14.220,00$ \\
\hline 4 & $\mathrm{R} \$ 16.800,00$ & $\mathrm{R} \$ 15.120,00$ \\
\hline 5 & $\mathrm{R} \$ 17.500,00$ & $\mathrm{R} \$ 15.750,00$ \\
\hline $\mathrm{I}$ & $13 \%$ & $13 \%$ \\
\hline VP (fVPL)? & $\mathrm{R} \$ 52.179,14$ & $\mathrm{R} \$ \mathbf{4 6 . 9 6 1 , 2 3}$ \\
\hline VPL ? & $\mathrm{R} \$ \mathbf{7 . 1 7 9 , 1 4}$ & $\mathrm{R} \$ 1.961,23$ \\
\hline TIR ? & $\mathbf{1 8 , 9 2} \%$ & $\mathbf{1 4 , 6 6 \%}$ \\
\hline Pay-back & $\mathbf{3}$ anos, 2 meses e $\mathbf{1 7}$ dias & $\mathbf{3}$ anos, $\mathbf{6}$ meses e $\mathbf{1 1}$ dias \\
\hline Pay-back Desc. & $\mathbf{4}$ anos, 2 meses e 21 dias & $\mathbf{4}$ anos, $\mathbf{6}$ meses e $\mathbf{1 5}$ dias \\
\hline
\end{tabular}

Fonte: Elaborado pelos autores.

Quadro 10 - Fluxo Real

\begin{tabular}{|l|l|l|l|l|}
\hline Anos & Fluxo & Fluxo Acumulado & Fluxo Descontado & Fluxo Desc. Acum. \\
\hline 0 & $-\mathrm{R} \$ 45.000,00$ & $-\mathrm{R} \$ 45.000,00$ & $-45.000,00$ & $-45.000,00$ \\
\hline 1 & $\mathrm{R} \$ 12.000,00$ & $-\mathrm{R} \$ 33.000,00$ & $10.619,47$ & $-34.380,53$ \\
\hline 2 & $\mathrm{R} \$ 13.800,00$ & $-\mathrm{R} \$ 19.200,00$ & $10.807,42$ & $-23.573,11$ \\
\hline 3 & $\mathrm{R} \$ 15.800,00$ & $-\mathrm{R} \$ 3.400,00$ & $10.950,19$ & $-12.622,91$ \\
\hline 4 & $\mathrm{R} \$ 16.800,00$ & $\mathrm{R} \$ 13.400,00$ & $10.303,75$ & $-2.319,16$ \\
\hline 5 & $\mathrm{R} \$ 17.500,00$ & $\mathrm{R} \$ 30.900,00$ & $9.498,30$ & $7.179,14$ \\
\hline
\end{tabular}

Fonte: Elaborado pelos autores.

Quadro 11 - Fluxo Conservador

\begin{tabular}{|l|l|l|l|l|}
\hline Anos & Fluxo & Fluxo Acumulado & Fluxo Descontado & Fluxo Desc. Acum. \\
\hline 0 & $-\mathrm{R} \$ 45.000,00$ & $-\mathrm{R} \$ 45.000,00$ & $-45.000,00$ & $-45.000,00$ \\
\hline 1 & $\mathrm{R} \$ 10.800,00$ & $-\mathrm{R} \$ 34.200,00$ & $9.557,52$ & $-35.442,48$ \\
\hline 2 & $\mathrm{R} \$ 12.420,00$ & $-\mathrm{R} \$ 21.780,00$ & $9.726,68$ & $-25.715,80$ \\
\hline 3 & $\mathrm{R} \$ 14.220,00$ & $-\mathrm{R} \$ 7.560,00$ & $9.855,17$ & $-15.860,62$ \\
\hline 4 & $\mathrm{R} \$ 15.120,00$ & $\mathrm{R} \$ 7.560,00$ & $9.273,38$ & $-6.587,24$ \\
\hline 5 & $\mathrm{R} \$ 15.750,00$ & $\mathrm{R} \$ 23.310,00$ & $8.548,47$ & $1.961,23$ \\
\hline
\end{tabular}

Fonte: Elaborado pelo autor.

Pode-se concluir que o projeto é viável, pois tanto no fluxo real como no fluxo conservador, o VPL é maior do que zero e também a TIR é maior que a TMA. Podendo, desta forma, sugerir aos sócios da Multieventos a possibilidade de investimento neste projeto. 
CASSOL, N. K.; SILVEIRA, A., HOELTGEBAUM, M. Empreendedorismo feminino: análise da produção científica da base de dados do Institute for Scientific Information (ISI), 1997-2006. Encontro da ANPAD. Rio de Janeiro, 2007.

CASAROTTO FILHO, N.; KOPITTKE, B.H. Análise de Investimentos. 9. ed. São Paulo: Editora Atlas S.A., 2000

COBRA, M. Marketing essencial: conceitos, estratégias e controle. São Paulo: Atlas, 1986.

COMAN, A., RONEN, B. Focused SWOT: diagnosign critical strenghts and weakness. In: International Journal of Production Research, 2009.

DE MORI, F. Empreender: identificando, avaliando e planejando um novo negócio. Florianópolis: Escola de Novos Empreendedores, 1998.

DORNELAS, J. C. A. Empreendedorismo na prática: mitos e verdades do empreendedor de sucesso. Rio de Janeiro: Elsevier, 2007.

FISHER, A.G. - Production, primary, secondary and tertiary, Economic Record, n.15, Junho. 1939.

FLEISCHER, G. A. Teoria da aplicação do capital: um estudo das decisões de investimento. São Paulo: Edgard BG, 1973.

GiMENEZ, S. C.; GIMENEZ, F. A. P. Atitude empreendedora e estratégia em pequenos e médios hotéis. Revista Turismo Visão e Ação - Eletrônica. V. 12, n.1, p.51-72, jan/abr, 2010.

GITMAN, L. J. Princípios de administração financeira. São Paulo: Harbra, 1997.

GRUNDY, Tony. Rethinking and reinventing Michael Porter's five forces model. in Wiley InterScience; 2006.

GUIMARÃES, T. B. C. Análise epistemológica do campo do empreendedorismo. Encontro da ANPAD. Rio de Janeiro, 2004.

IBGE - Instituto Brasileiro de Geografia e Estatística. Disponível em: <http://www.ibge.gov.br/cidadesat/ topwindow.htm?1>. Acesso em 28 mar. 2011.

IMÓVEIS \& CIA. Tendência para o mercado imobiliário de Balneário Camboriú e região. Disponível em: http://imoveiseciaonline.com/detalhadica.php?cod=13. Acesso em: 12 dez. 2012.

KON, A. Evolução do setor terciário brasileiro. Relatório n.14. EAESP/FGV. 1996.

Sobre as Atividades de Serviços: Revendo Conceitos e Tipologias. Revista de Economia Política. Vol. 19. n. 2. 1999.

KOTLER, P. Marketing estratégico para instituições educacionais. São Paulo: Atlas, 1994.

Administração de Marketing: análise, planejamento, implementação e controle. Tradução Ailton Bomfim Brandão. 4. ed. São Paulo: Atlas, 1991.

KOTLeR, P., ARMSTRONG, G. Princípios de marketing. Tradução de Arlete Simille Marques e Sabrina Cairo. 9. ed. São Paulo: Prentice Hall, 2003.

LAS CASAS, A. L. Marketing de serviços. São Paulo: Atlas, 1991.

LIMA FILHO, A. O. Marketing de Serviços; 2001. Disponível em: www.portaldomarketing.com. br/

LONGENECKER, J. G., MOORE, C. W., PETTY, J. W. Administração de pequenas empresas: ênfase na gerência empresarial. São Paulo: Makron Books, 1997.

LOVELOCK, C.; WRIGHT, L. Serviços de Marketing e Gestão. Ed. Saraiva, 2001.

OLIVEIRA, J. A.N. Engenharia econômica: uma abordagem as decisões de investimento. São Paulo: McGraw-Hill, 1982. 
O SOL DIÁRIO. Construtoras voltam os olhos para a classe média em Balneário Camboriú. Disponível em: http://osoldiario.clicrbs.com.br/sc/economia/noticia/2012/09/ construtoras-voltam-os-olhos-para-aclasse-media-em-balneario-camboriu-3888673.html. Acesso em: 12 dez. 2012.

PAIVA JR., F. G.; CORDEIRO, A. T. Empreendedorismo e espírito empreendedor: uma análise da evolução dos estudos na produção acadêmica brasileira. ENANPAD, 2002.

PEREIRA, H. J. Criando seu próprio negócio: como desenvolver o potencial empreendedor. Brasília: Ed. SEBRAE, 1995.

PREFEITURA MUNICIPAL DE BALNEÁRIO CAMBORIÚ. Disponível em: <http://www.balneariocamboriu. sc.gov.br>. Acesso em: 27 out. 2010.

RATHMELL, J. M. - apud COBRA, Marcos. Marketing de serviços: conceitos e estratégias. São Paulo, McGraw-Hill do Brasil, 1986.

RIDDLE, D.I. - Service-led growth: The role of the service sector in world development. Nova York: Praegers Publishers. 1986.

SANTUR - Santa Catarina Turismo. Disponível em: < http://www.santur.sc.gov.br/ >. Acesso em 28 mar. 2011.

SILVA, J. P. Análise financeira das empresas. 7. ed. São Paulo: Atlas, 2005.

STONER, J. A. F.; FREEMAN, R. E. Administração. Rio de Janeiro: Prentice Hall do Brasil, 1995.

TARAPANOFF, K. Inteligência Organizacional e Competitiva. Brasília: UNB, 2001.

TEIXEIRA, S. Planeamento e Gestão das Organizações, 2005, pp. 49-69.

WALKER, R. A. "Is There a Service Economy? The changing capitalist division of labor", em Science and Society, vol. XLIX, n. 1, Spring, 1985. 